\title{
Classification of Travertine Tiles with Supervised and Unsupervised Classifiers and Quality Control
}

\author{
Nazan Kemaloglu, Tuncay Aydogan, and Sedat Metlek
}

\begin{abstract}
Natural stone tiles, which are used in decoration field, should be in a specific visual standard. In order to meet this expectation, it is very important that the tiles be classified before being packed. Especially in operation where exports of processed natural stones are increasing, all steps from cutting to packing must be done with the least mistakes. In the natural stone sector, selection workers are mostly used for classification and packaging operations. This situation; changing environmental factors such as light, temperature, can result in errors due to the fact that the human eye tends to get tired and lose perception over time. Therefore, there is a need for an automation system that can be used correctly for classification. Along with developing technologies, it is seen that the errors that can occur in classification can be reduced to a minimum. In this study both of supervised and unsupervised algorithms were used and it was tried to determine which classifier and dataset gave the most accurate result. Besides this, the corner fractures of the travertine tiles were also detected and quality control was made.
\end{abstract}

Index Terms-Travertine classification, surface analysis, bayes classification, quality control.

\section{INTRODUCTION}

Turkey is in the upper ranks between the world's major natural stone producers with its reserves and the developing natural stone industry. Export line of the sector is developing with the investments made. In particular, demand for processed natural stone from abroad is in a continuous increase [1].

Classification in the natural stone sector is mostly done by selection workers. In this manual classification process, mistakes are often encountered. The main reasons for this are; the workers used for classification are misclassified with environmental factors such as light and temperature and the occurrence of losses in perceptions of their employed for classification [2], [3].

Various studies are being made to solve this problem in the natural stone sector, which has an important place in the Turkish economy. Common view of these studies; it has been seen that an automation system working in place of the human hand at the classification stage will solve this problem to a great extent [2]-[6].

Classification methods, classify the data based on features

Manuscript received November 3, 2017; revised January 12, 2018.

Nazan Kemaloglu is with the Department of Computer Engineering, Suleyman Demirel University, Turkey (e-mail: nzn_kemaloglu@hotmail.com).

Tuncay Aydogan is with the Department of Software Engineering, Suleyman Demirel University, Turkey (e-mail: tuncayaydogan@sdu.edu.tr).

Sedat Metlek is with the Department of Mechatronics, Mehmet Akif Ersoy University, Turkey (e-mail: sedatmetlek@mehmetakif.edu.tr). that extracted from them. These features can be extracted from the given data with various operations [2], [4], [7], [8].

All extracted features may not be usable. At this point, selection process can be done with various feature selection algorithms [3], [8], [9].

In addition to classification, there is also the detection and quality control of fractures occurring in natural stones in the literature, morphological processing steps such as erosion, dilation, opening etc. are applied for this process [10]-[14].

In this study, travertine tiles are classified through the features that extracted and examined from them. In the course of classification, it has been tried to find a classification algorithm suitable to the dataset by using classification algorithms which are supervised and not unsupervised. Corner fractures were also detected, and broken natural stones were removed from dataset. All studies made with MATLAB R2015a.

\section{MorPhOlOGICAL PRE-PROCESSING}

\section{A. Morphological Closing}

Morphological closure is used to join the broken objects on the image and to fill in the gaps. The application is implemented on the binary image with the help of any structural element. The structural element to be used is circulated on the image and the closing operation is completed [15], [16]. The morphological closing process is expressed by Eq. (1).

$$
\mathrm{A} \cdot \mathrm{B}=(\mathrm{A} \oplus \mathrm{B}) \ominus \mathrm{B}
$$

where, $\mathrm{A}$ is binary image as an input image and $\mathrm{B}$ is structural element.

\section{FEATURE EXTRACTION}

The values to be considered in the classification phase are the attributes that will represent the dataset in hand. With these features, the general characteristics of the classes can be established. On the other hand, classification makes use of different relations between these features to distinguish between the available data. Gray Level Co- Occurrence Matrices (GLCM) is one of the best known tissue analysis tools for calculating second order statistical features of the view [17].

The GLCM describes the relationship between neighboring pixels on the image. This relationship indicates the number of occurrences and the brightness levels in the pixel pairs at a constant distance and the direction [18]. Statistical properties such as contrast, energy, correlation and 
contrast can be calculated with GLCM.

\section{A. Feature Extraction from Color Analysis}

Texture represents the statistical properties of pixel density. Texture analysis is one of the methods used in feature extracting.

$$
\begin{gathered}
\text { Energy }=\sum_{i, j} P_{i, j}^{2} \\
\text { Contrast }=\sum_{i, j}|i-j|^{2} P_{i, j} \\
\text { Correlation }=\frac{\sum_{\mathrm{i}, \mathrm{j}}(\mathrm{ij}) \mathrm{P}_{\mathrm{ij}}-\mu_{\mathrm{x}} \mu_{\mathrm{y}}}{\sigma_{\mathrm{x}} \sigma_{\mathrm{y}}} \\
\text { Homogenity }=\sum_{i j} \frac{P_{i j}}{1+|i-j|} \\
\text { Entropy }=-\sum_{\mathrm{ij}} \mathrm{P}_{\mathrm{ij}} \log \mathrm{ij}
\end{gathered}
$$

where; $P_{i j}$ is probability density function and $\mu_{x}, \mu_{y}, \sigma_{x}$ and $\sigma_{y}$ are the mean and standard deviation of the rows and columns of $P_{i j}$ [19].

\section{B. Feature Extraction from Texture Analysis}

Color spaces are mathematical models that represent colors. According to Grassmann's first law, each color is represented by 3 independent variables. For this reason, color spaces are modeled in 3D [20].

The RGB color space alone is not enough for the feature extraction phase. Therefore, other color spaces are also analyzed.

HLS color space, consist (H: Hue), (L: Lightness) and (S: Saturation) values. HLS is converted from RGB color space by non-linear methods as shown Eq. (7) [8] [21].

$$
H= \begin{cases}\varepsilon & , \text { If } B \leq G \\ 2 \pi-\varepsilon, & \text { others }\end{cases}
$$

where $\varepsilon$;

$$
\begin{gathered}
\varepsilon=\arccos \frac{(R-G)+(R+B)}{\sqrt{2\left[(R-G)^{2}+(R-B)^{2}+(G-B)^{2}\right]}} \\
S=1-\frac{\min (R, G, B)}{L} \\
L=\frac{R+G+B}{2}
\end{gathered}
$$

The LMS color space that obtained from RGB space by linear methods, consists of Long (L), Medium (M), Short (S) components as shown Eq. (8) [22].

$$
\begin{gathered}
L \\
S
\end{gathered}=\left[\begin{array}{lll}
0.381 & 0.578 & 0.040 \\
0.196 & 0.724 & 0.078 \\
0.024 & 0.128 & 0.844
\end{array}\right] \bullet\left[\begin{array}{l}
R \\
G \\
B
\end{array}\right]
$$

The OHTA color space that developed by Ohta in 1980, is a linear color space transformation. Ohta color space is obtained according to Eq. (9) [23] [24].

$$
\begin{aligned}
& I_{1} \\
& I_{2} \\
& I_{3}
\end{aligned}=\left[\begin{array}{ccc}
1 / 3 & 1 / 3 & 1 / 3 \\
1 / 2 & 0 & -1 / 2 \\
-1 / 2 & 1 & -1 / 2
\end{array}\right] \bullet\left[\begin{array}{l}
R \\
G \\
B
\end{array}\right]
$$

The YCbCr color space that obtained from RGB space by linear methods, consists of $\mathrm{Y}$ (Luminance), $\mathrm{Cb}$ and $\mathrm{Cr}$ (chrominance information) components as shown Eq. (10) [25], [26].

$$
\begin{aligned}
& Y \\
& C_{b} \\
& C_{r}
\end{aligned}=\left[\begin{array}{ccc}
0.299 & 0.587 & 0.114 \\
-0.169 & -0.331 & 0.5 \\
0.5 & -0.419 & -0.081
\end{array}\right] \cdot\left[\begin{array}{l}
R \\
G \\
B
\end{array}\right]+\left[\begin{array}{c}
0 \\
128 \\
128
\end{array}\right]
$$

$\mathrm{YPbPr}$ is a linearly transformed color space, representing the analog shape of the $\mathrm{YCbCr}$ color space [8] [27].

$$
\begin{aligned}
& Y \\
& P_{b} \\
& P_{r}
\end{aligned}=\left[\begin{array}{ccc}
0.299 & 0.587 & 0.114 \\
-0.168 & -0.232 & -0.064 \\
0.499 & -0.418 & -0.081
\end{array}\right] \bullet\left[\begin{array}{l}
R \\
G \\
B
\end{array}\right]
$$

$$
\mathrm{Y} \in[0,255]
$$

$\mathrm{P}_{\mathrm{b}} \in[-127.5,+127.5]$ From color spaces, statistical data

$\mathrm{P}_{\mathrm{r}} \in[-127.5,+127.5]$

such as general average, standard deviation and gray thresh value can be obtained.

\section{Fisher FEATURE SELECTION ALGORITHM}

Fisher's feature selection algorithm, which uses arithmetic mean and standard deviation values of classes, is an effective method for filtering. With this method, it is possible to remove noisy data to obtain a subset of features in large data sets [28] [29]. Eq. 12 is used to find the transformation matrix to be used when selecting the existing features.

$$
J(W)=\max \frac{\left|W^{T} S_{B} W\right|}{\left|W^{T} S_{W} W\right|}
$$

where; W is transformation matrix, $\boldsymbol{S}_{\boldsymbol{W}}$ is in-class scatter matrix and $\boldsymbol{S}_{\boldsymbol{B}}$ is inter-class scatter matrix.

Scatter matrices are given in Eq. 13 and Eq. 14.

$$
\begin{aligned}
S_{W} & =\sum_{i=1}^{C} \sum_{m=1}^{N_{i}}\left(x_{m}^{i}-\mu_{i}\right)\left(x_{m}^{i}-\mu_{i}\right)^{T} \\
S_{B} & =\sum_{i=1}^{C} N_{i}\left(\mu_{i}-\mu\right)\left(\mu_{i}-\mu\right)^{T}
\end{aligned}
$$

where; $\mathrm{C}$ is class number, $N_{i}$ is data number in each class, $x_{m}$ is $\mathrm{m}$. data in each class, $\mu_{i}$ is average values of i. class and $\mu$ is total average for every data [3].

\section{BAYESIAN CLASSIFICATION}

Bayes, which is basically referred to as a hypothesis, approaches the classification process as a probabilistic problem [30] [31]. The properties used in Bayesian classifiers can be expressed as follows

$$
\Omega=\left\{w_{1}, w_{2}, \ldots, w_{n}\right\}
$$

where; ' $\Omega$ is $\mathrm{n}$ sets of finite natural states (pattern recognition set) and

$$
A=\left\{a_{1}, a_{2}, \ldots, a_{s}\right\}
$$

where; $A$ is s possible decisions group and $\underline{x} \in \mathrm{R}^{d}$ is defined as the $\mathrm{d}$ component feature vector.

From here; 
$\mathrm{p}\left(\underline{\mathrm{x}} \mid \mathrm{w}_{\mathrm{j}}\right) ;$; is the conditional probability density function for $(\underline{x})$,

$\mathrm{p}\left(\mathrm{w}_{\mathrm{j}}\right) ; ; \quad$ is priori probability of natural $\left(w_{j}\right)$,

$\mathrm{p}\left(\mathrm{w}_{\mathrm{j}}|\underline{\mathrm{x}}|\right) \mathrm{p}\left(\mathrm{w}_{\mathrm{j}}|\underline{\mathrm{x}}|\right)$; is posteriori probability.

When the probabilities are combined with Bayes Rule;

$$
p\left(w_{j}|\underline{x}|\right)=\frac{p\left(\underline{x} \mid w_{j}\right) p\left(w_{j}\right)}{p(\underline{x})}
$$

where; $p(\underline{x})$ is,

$$
p(\underline{x})=\sum_{j=1}^{n} p\left(\underline{x} \mid w_{j}\right) p\left(w_{j}\right)
$$

By Bayes decision rule, if

$$
p\left(w_{i}|\underline{x}|\right)>p\left(w_{j}|\underline{x}|\right)
$$

Decision is; $w_{i} \quad(\forall j \neq i)$ [31] [32] [33].

The Bayes decision rule shows how best the classifier should be designed, if known for preliminary probabilities $p\left(w_{j}\right)$ and class conditional densities $p\left(\underline{x} \mid w_{j}\right)$ [34].

\section{FuZZY C-MEANS ClassifiCATION}

The Fuzzy C-Means algorithms, which have the widest use of fuzzy clustering algorithms, aim to reduce the objective function [35], [36].

The Fuzzy C-Means algorithms allow each object to belong to more than one class. The algorithm assigns a membership value to each object in the range $[0,1]$ for each class. The sum of membership values for all classes is 1 and the class that has the greatest membership value is determined as the class to which the object belongs [8], [37].

In the algorithm, the optimum value is obtained by converging the objective function to the determined minimum value and classification is complete [38], [39].

The objective function is given in Eq. (20).

$$
J=\sum_{j=1}^{N} \sum_{i=1}^{C} u_{i j}^{m}\left\|x_{j}-v_{i}\right\|^{2}
$$

where; $u_{i j}$ is $\boldsymbol{i}^{\text {th }}$ class' $x_{j}$ pixel element, $v_{i}$ is $\boldsymbol{i}^{\text {th }}$ cluster center, $\mathrm{m}$ is the center of gravity that controls the fuzzy by varying from 1 to $\infty$. After the initial membership matrix is randomly assigned, the center vectors are updated according to Eq. (21) and Eq. (22).

$$
C_{j}=\frac{\sum_{i=1}^{N} u_{i j}^{m} x_{i}}{\sum_{i=1}^{N} u_{i j}^{m}}
$$

$\mathrm{U}$ membership value is recalculated according to the calculated cluster centers.

$$
\left.u_{i j}=\frac{1}{\sum_{k=1}^{C}\left(\left\|x_{i}-c_{i}\right\|\right.}\right)^{2 /(m-1)}
$$

The membership matrix U containing the fuzzy values as a result of the operation shows the result of the clustering [8] [37].

\section{RESULTS}

Travertine samples of two classes were used for the works. These class are called AT (Class-1) for first nine samples and KT (Class-2) for least nine samples, as shown in Fig. 1.
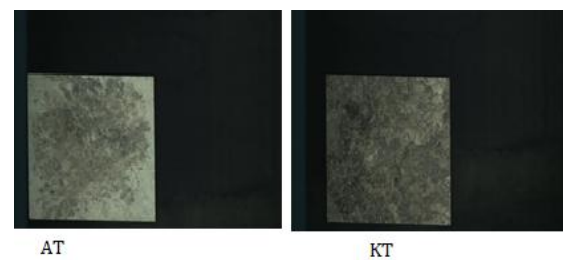

Fig. 1. Travertine tiles' samples.

Firstly, background subtraction is applied all images. These images contain black background pixels. So the value read from the matrix is 10 pixels inside (Fig. 2).
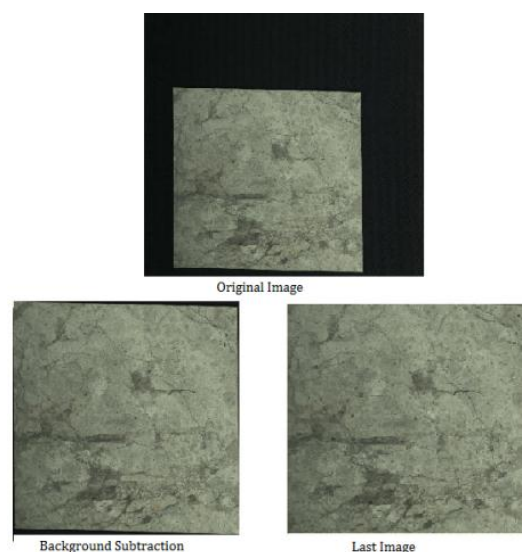

Fig. 2. Getting the used image from original image.

For the fractal detection, image with background is used. Firstly, image converted to binary form. Then morphological closing is applied and image frame is detected. After this step the sum of pixel values (SPV) is calculated for quality control (QC). The total value differs according to the used resolution value. In this study, the sum of pixel values is determined to be 220000 and above, the sturdy tile (ST) and if less than 220000, the broken tile (BT) as shown Eq. (23) and Fig. 3.

$$
\mathrm{QK}=\left\{\begin{array}{l}
\mathrm{SP}, \mathrm{IfSPV} \geq 220000 \\
\mathrm{BP}, \mathrm{IfSPV}>220000
\end{array} \quad \mathrm{QK}=\right.
$$

SSP, IfSPV $\geq 220000$

$\{\mathrm{BP}$, IfSPV $<220000$
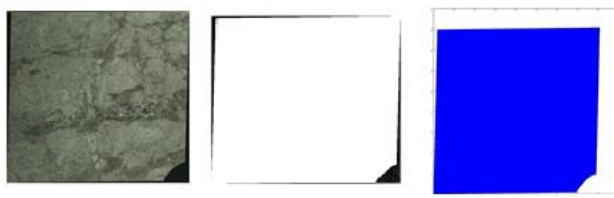

Broken product
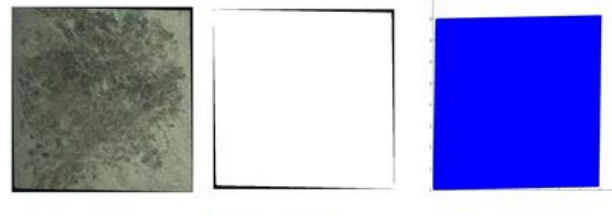

Sturdy product

Fig. 3. Fractal detection.

After the fractal detection, remaining sturdy natural stones 
has been studied for classification. Total of 17 color spaces, including the RGB color space, were tested in this study. Various features were extracted by texture analysis from each color space (Table I).

TABLE I: EXTRACTED FEATURES

\begin{tabular}{l|c}
\hline Feature Type & Number of Features \\
\hline Average of each color component & 3 \\
\hline $\begin{array}{c}\text { General average of color space } \\
\text { General standard deviation of color }\end{array}$ & 1 \\
\hline $\begin{array}{l}\text { Standard deviation of each color } \\
\text { component }\end{array}$ & 3 \\
\hline Contrast & 1 \\
\hline Homogeneity & 1 \\
\hline Energy & 1 \\
\hline Correlation & 1 \\
\hline Entropy & 1 \\
\hline
\end{tabular}

Features specified in Table I were extracted from 17 color spaces during the attribute extraction phase, and consequently, 238 features were obtained for each travertine.

Not all of the features are suitable for use. Therefore, by examining the features, the ones that can distinguish 2 classes have been determined and reduced to 42 features. Five features were selected by Fisher feature selection algorithm in order to determine the most efficient for classification from the 42 features in the hand. Selected features are given in Table 2 .

\begin{tabular}{c|c|c}
\hline \multicolumn{3}{c}{ TABLE II: SELECTED FEATURES WITH FISHER } \\
\hline $\begin{array}{c}\text { Feature } \\
\text { No }\end{array}$ & $\begin{array}{l}\text { Best Number of } \\
\text { Feature }\end{array}$ \\
\hline 34 & $\begin{array}{c}\text { Standard deviation of } \\
\text { JPEG-YCbCr }\end{array}$ & 1 \\
\hline 32 & $\begin{array}{c}\text { Average of YPbPr - Pr } \\
\text { Component }\end{array}$ \\
\hline 41 & Entropy of OHTA & 3 \\
\hline 34 & Standard deviation of HSL & 4 \\
\hline 33 & Gray Thresh of LMS & 5 \\
\hline
\end{tabular}

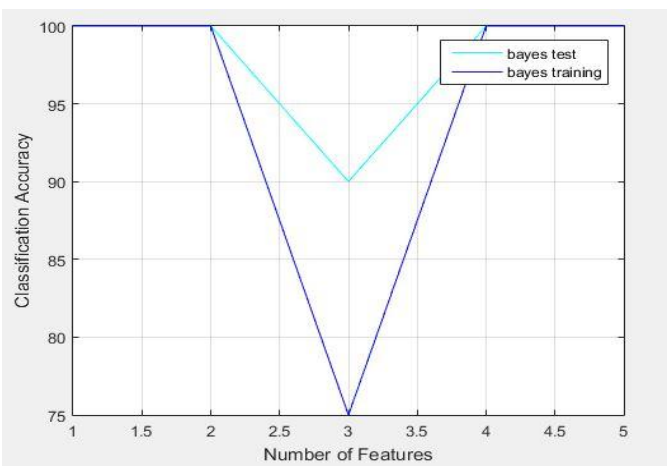

Fig. 4. Classification accuracy graphic for bayes.

First, the selected 5 features are classified with Bayes, which is a supervised classification algorithm. The available feature matrix for Bayes is divided into $40 \%$ training and $60 \%$ test. Used for this step PR-Tools in MATLAB. This tool chooses training and test sets at different region in feature matrix for every time. The rate of recognition of the test data of the trained classifier by the training data is given in Fig. 2 .
The numerical values of the same graph are shown in Table III.

TABLE III: CLASSIFICATION ACCURACY RATE FOR BAYES

\begin{tabular}{l|c}
\hline Feature Name & $\begin{array}{l}\text { Classification } \\
\text { Accuracy }\end{array}$ \\
\hline Standard deviation of JPEG-YCbCr & $100 \%$ \\
\hline Average of YPbPr Pr & $100 \%$ \\
\hline Entropy of OHTA & $90 \%$ \\
\hline Standard deviation of HSL & $100 \%$ \\
\hline Gray Thresh of LMS & $100 \%$ \\
\hline General classification success & $98 \%$ \\
\hline
\end{tabular}

The fuzzy C-means algorithm, which is one of the fuzzy clustering methods and is frequently used for classification in the literature, is used as an unsupervised classifier. Threshold values for 5 selected features were determined by Fisher feature selection algorithm and given to Fuzzy C-Means algorithms as input (Table IV).

TABLE IV: FuZZY C-MEANS' THRESHOLD VALUES

\begin{tabular}{|c|c|c|c|}
\hline Thresh & Feature Name & $\begin{array}{l}\text { AT } \\
(\text { Class-1) of } \\
\text { Thresh }\end{array}$ & $\begin{array}{l}\text { KT } \\
\text { (Class-2) of } \\
\text { Thresh }\end{array}$ \\
\hline (T1) & $\begin{array}{l}\text { Standard } \\
\text { deviation of } \\
\text { JPEG-YCbCr }\end{array}$ & $(\mathrm{T} 1)<20$ & $(\mathrm{~T} 1)>20$ \\
\hline (T2) & $\begin{array}{ll}\text { Average } & \text { of } \\
\text { YPbPr } & \operatorname{Pr} \\
\text { Component } & \end{array}$ & $\begin{array}{r}(\mathrm{T} 2) \\
<0.021\end{array}$ & $\begin{array}{ll} & (\mathrm{T} 2)>0.02 \\
1 & \end{array}$ \\
\hline (T3) & $\begin{array}{l}\text { Entropy of } \\
\text { OHTA }\end{array}$ & (T3) <4.20 & $(\mathrm{T} 3)>4.20$ \\
\hline (T4) & $\begin{array}{l}\text { Standard } \\
\text { deviation } \\
\text { HSL }\end{array}$ & (T4) $>90$ & $(\mathrm{~T} 4)<90$ \\
\hline (T5) & $\begin{array}{l}\text { Gray Thresh of } \\
\text { LMS }\end{array}$ & $(\mathrm{T} 5)<0.55$ & $(\mathrm{~T} 5)>0.55$ \\
\hline
\end{tabular}

The membership values for Class- 1 (AT) and Class-2 (KT) of each data are given in Table $\mathrm{V}$ and Table VI.

TABLE V: MEMBERSHIP RATE FOR AT (CLASS- 1)

\begin{tabular}{l|l|l|l|l|l}
\hline $\begin{array}{l}\text { Tile } \\
\text { No }\end{array}$ & \multicolumn{5}{|l}{ Feature No } \\
\hline & 1 & 2 & 3 & 4 & 5 \\
\hline 1 & 0.9956 & 0.9999 & 0.9957 & 0.8794 & 0.9129 \\
\hline 2 & 0.9888 & 0.9864 & 0.9891 & 0.9993 & 0.9906 \\
\hline 3 & 0.9677 & 0.9733 & 0.9677 & 0.8677 & 0.9652 \\
\hline 4 & 0.9984 & 0.9970 & 0.9985 & 0.9448 & 0.9990 \\
\hline 5 & 0.9872 & 0.9816 & 0.9872 & 0.9348 & 0.9962 \\
\hline 6 & 0.9979 & 0.9999 & 0.9978 & 0.9122 & 0.9923 \\
\hline 7 & 0.9439 & 0.9637 & 0.9439 & 0.9284 & 0.9564 \\
\hline 8 & 0.9984 & 0.9977 & 0.9985 & 0.9531 & 0.9985 \\
\hline 9 & 0.9773 & 0.9777 & 0.9776 & 0.9143 & 0.9520 \\
\hline 10 & 0.9328 & 0.9518 & 0.9319 & 0.7553 & 0.8999 \\
\hline 11 & 0.8370 & 0.9007 & 0.8351 & 0.6038 & 0.7399 \\
\hline 12 & 0.7827 & 0.8334 & 0.7804 & 0.7912 & 0.8643 \\
\hline 13 & 0.9152 & 0.9519 & 0.9119 & 0.9252 & 0.9681 \\
\hline 14 & 0.1651 & 0.1900 & 0.1620 & 0.0234 & 0.2270 \\
\hline 15 & 0.8976 & 0.8959 & 0.8957 & 0.6195 & 0.8945 \\
\hline 16 & 0.0087 & 0.0075 & 0.0093 & 0.0107 & 0.0034 \\
\hline 17 & 0.0577 & 0.0585 & 0.0588 & 0.0812 & 0.0547 \\
\hline 18 & 0.0117 & 0.0224 & 0.0109 & 0.0002 & 0.0020 \\
\hline & & & & &
\end{tabular}

TABLE VI: MEMBERSHIP RATE FOR KT (CLASS- 2)

\begin{tabular}{c|c|c|c|c|c}
\hline $\begin{array}{l}\text { Tile } \\
\text { No }\end{array}$ & \multicolumn{5}{|c}{ Feature No } \\
\hline & 1 & 2 & 3 & 4 & 5 \\
\hline 1 & 0.0044 & 0.0001 & 0.0043 & 0.1206 & 0.0871 \\
\hline 2 & 0.0112 & 0.0136 & 0.0109 & 0.0007 & 0.0094 \\
\hline 3 & 0.0323 & 0.0267 & 0.0323 & 0.1323 & 0.0348 \\
\hline 4 & 0.0016 & 0.0030 & 0.0015 & 0.0552 & 0.0010 \\
\hline
\end{tabular}




\begin{tabular}{r|l|l|l|l|l}
\hline 5 & 0.0128 & 0.0184 & 0.0128 & 0.0652 & 0.0038 \\
\hline 6 & 0.0021 & 0.0001 & 0.0022 & 0.0878 & 0.0077 \\
\hline 7 & 0.0561 & 0.0363 & 0.0561 & 0.0716 & 0.0436 \\
\hline 8 & 0.0016 & 0.0023 & 0.0015 & 0.0469 & 0.0015 \\
\hline 9 & 0.0227 & 0.0223 & 0.0224 & 0.0857 & 0.0480 \\
\hline 10 & 0.0672 & 0.0482 & 0.0681 & 0.2447 & 0.1001 \\
\hline 11 & 0.1630 & 0.0993 & 0.1649 & 0.3962 & 0.2601 \\
\hline 12 & 0.2173 & 0.1666 & 0.2196 & 0.2088 & 0.1357 \\
\hline 13 & 0.0848 & 0.0481 & 0.0881 & 0.0748 & 0.0319 \\
\hline 14 & 0.8349 & 0.8100 & 0.8380 & 0.9766 & 0.7730 \\
\hline 15 & 0.1024 & 0.1041 & 0.1043 & 0.3805 & 0.1055 \\
\hline 16 & 0.9913 & 0.9925 & 0.9907 & 0.9893 & 0.9966 \\
\hline 17 & 0.9423 & 0.9415 & 0.9412 & 0.9188 & 0.9453 \\
\hline 18 & 0.9883 & 0.9776 & 0.9891 & 0.9998 & 0.9980 \\
\hline
\end{tabular}

According to Table V and Table VI, the first 9 samples and samples 14, 16, 17, 18 were transferred to the right class, whereas the samples $10,11,12,13$ and 15 were transferred to the wrong class. Looking at the same tables, it is seen that the sum of the membership rates of each sample in the same feature AT (Class-1) and KT (Class-2) is 1. The classification success is given in Table VII.

TABLE VII: CLASSIFICATION ACCURACY RATE FOR FUZZY C-MEANS

\begin{tabular}{l|l}
\hline Classification accuracy rate for 1st feature & $72.22 \%$ \\
\hline Classification accuracy rate for 2nd feature & $72.22 \%$ \\
\hline Classification accuracy rate for 3rd feature & $72.22 \%$ \\
\hline Classification accuracy rate for 4 th feature & $72.22 \%$ \\
\hline Classification accuracy rate for 5th feature & $72.22 \%$ \\
\hline
\end{tabular}

The classification performance given in Table VII was found to be the same for all features in fuzzy c-means algorithm.

\section{CONCLUSION}

A total of 18 samples of both classes were used in this study. The products's size is $15 \times 15 \mathrm{~cm}$. In the detection of broken travertine, it was tried to find the exact area of the travertine. The threshold value determined for fracture detection can be changed according to the pixel values of the image So if this process is applied to products that are different sizes, the threshold value (SPV) will definitely change. Besides this, the process is worked only for corner fractures. It is predicted that a study can be made in the future, for detection small-scale fractures along the edges of the travertine.

The results obtained show that the data used is not suitable for unsupervized learning. The fuzzy C-Means algorithm failed to exceed $72.2 \%$ classification success, nevertheless, 98\% success was achieved in classification with the supervised Bayes algorithm.

The result obtained compares Bayes and fuzzy c-means classifiers in the classification phase. The fuzzy C-Means algorithms have achieved a fairly low success rate against the Bayes classifier. This shows that the supervised classification algorithm is one of the most important elements that provides success in the data set. When classifying, comparison from pre-trained data is the most suitable method in the developed system.

The Fuzzy C-Means algorithms, which classify the data according to the degree of membership according to their proximity to the determined cluster centers, failed to achieve the desired performance in the system. According to literature, the Fuzzy C-Means algorithms, which are frequently used clustering methods with a high success rate in the classification phase of the travertine tiles, are insufficient in this study. The reason for this is that the different in-class data are close together and the data is divided into two classes. It is envisaged that if number of samples are increased, classification accuracy can achieve a high success rate with Fuzzy C-Means algorithms.

\section{ACKNOWLEDGMENT}

The authors would like to thank to Süleyman Demirel University Research Project Coordination Unit (BAP) for support to 4536-YL1-16.

\section{REFERENCES}

[1] S. Yalçın and T. Uyanık, "The place of turkey in world marble trading," Turkey III. Marble Symposium 3-5 May 2001, s-397-416, Afyon.

[2] M. A. Selver and O. Akay, "Evaluating clustering methods for classification of marble slabs in an automated industrial marble inspection system," in Proc. International Conference on Electrical and Electronics Engineering.

[3] S. Metlek, "Automatic classification of natural stone plate with machine vision," Doctoral thesis, Suleyman Demirel Universty, Graduate School of Natural Sciences, Isparta, 2015.

[4] J. Martínez-Alajarín, J. D. Luis-Delgado, and L. M. Tomás-Balibrea, "Automatic system for quality-based classification of marble textures," IEEE Transactions on Systems, Man, and Cybernetics, Part C (Applications and Reviews), vol. 35, no. 4, 2005, pp. 488-497.

[5] M. A. Selver, O. Akay, F. Alim, S. Bardakçı, and M. Ölmez, "An automated industrial conveyor belt system using image processing and hierarchical clustering for classifying marble slabs," Robotics and Computer-Integrated Manufacturing, vol. 27, no. 1, 2011, pp. $164-176$

[6] Ö. Akkoyun, "An evaluation of image processing methods applied to marble quality classification," Turkey VII. International Marble and Natural Stone Congress, 2011.

[7] A. Selver, E. Ardali, and O. Akay, "Feature extraction for quantitative classification of marbles," ISignal Processing and Communications Applications, pp. 1-4, 2007.

[8] M. Şişeci, "Determination of travertine plate stones with clustering methods," Master thesis, Suleyman Demirel University, Graduate School of Natural Sciences, Isparta, 2012.

[9] A. Gümüşçü, İ. B. Aydilek, and R. Taşaltın, "Comparison of feature selection algorithms on microarray data classification," Harran Universty Engineering Journal, vol. 1, no. 1, 2016

[10] H. Elbehiery, A. Hefnawy, and M. Elewa, "Surface defects detection for ceramic tiles using 1mage processing and morphological techniques," World Academy of Science, Engineering and Technology International Journal of Computer, Electrical, Automation, Control and Information Engineering, vol. 1, no. 5, 2007, p. 52, 2005.

[11] G. M. Rahaman and M. Hossain, "Automatic defect detection and classification technique from image: A special case using ceramic tiles," International Journal of Computer Science and Information Security, vol. 1, no. 1, May 2009.

[12] R. Gonydjaja and B. T. M. Kusuma, "Rectangulary defect detection for ceramic tile using morphological techniques," ARPN Journal of Engineering and Applied Sciences, vol. 9, no. 11, 2014, pp. 2052-2056.

[13] G. Jacob, R. Shenbagavalli, and S. Karthika, "Detection of surface defects on ceramic tiles based on morphological techniques," Cornell University Library, 2016.

[14] S. Singh and M. Kaur, "Machine vision system for automated visual inspection of tile's surface quality," IOSR Journal of Engineering, vol. 2, pp. 429-432, 2012.

[15] M. Karhan, M. O. Oktay, Z. Karhan, and H. Demir, "Detecting spots on apricots due to coryneum beijerinckii disease with morphological 1mage processing methods," in Proc. 6th International Advanced Technologies Symposium, pp. 172-176, 2011.

[16] R. C. Gonzales and R. E. Woods, "Digital 1mage processing," Second Edition, Prentice Hall, 2002

[17] V. Göreke, E. Uzunhisarcıkll, and A. Güven, "Using gray level co-occurrence matrices obtaining texture features from 
mammogram and determination of the mass via artificial neural network," National Congress of Medical Technologies '14, 2014.

[18] Ö. Kayaaltı, B. H. Aksebzeci, İ. Ö. Karahan, K. Deniz, M. Öztürk, B. Yllmaz, and M. H. Asyalı, "Liver fibrosis staging using CT image texture analysis and soft computing," Applied Soft Computing, vol. 25, pp. 399-413, 2014

[19] A. Demirhan and I. Guler, "Image segmentation using self-organizing maps and gray level co-occurrence matrices," Journal of the Faculty of Engineering and Architecture of Gazi University, vol. 25, no. 2, pp. 285-291, 2010

[20] İ. Yılmaz, M. Güllü, T. Baybura, and A. O. Erdoğan, "Color spaces and color conversion programme (CCP)," Afyon Kocatepe Universty Journal of Science and Engineering Sciences, vol. 2, no. 2, 2002, pp. 19-35.

[21] C. Balas, "An imaging colorimeter for noncontact tissue color mapping," IEEE transactions on Biomedical Engineering, vol. 44, no. 6, 1997, pp. 468-474.

[22] E. Reinhard, M. Adhikhmin, B. Gooch, and P. Shirley, "Color transfer between images," IEEE Computer Graphics and Applications, vol. 21 , no. 5, pp. 34-41, 2001

[23] V. Jayakrishna, G. P. Akhila, and S. Basher, "Advanced hybrid color space normalization for human face extraction and detection," International Journal for Scientific Research and Development, vol. 1, no. 4, 2013, pp-1043-1053.

[24] Y. I. Ohta, T. Kanade, and T. Sakai, "Color information for region segmentation," Computer Graphics and İmage Processing, vol. 13, no. 3, pp. 222-241, 1980

[25] X. Wang, C. Hu, and S. Yao, "An adult image recognizing algorithm based on naked body detection," in Proc. ISECS International Colloquium on Computing, Communication, Control, and Management, 2009, pp. 197-200.

[26] J. A. M. Basilio, G. A. Torres, G. S. Pérez, L. K. T. Medina, and H. M. P. Meana, "Explicit image detection using $\mathrm{YCbCr}$ space color model as skin detection," Applications of Mathematics and Computer Engineering, pp. 123-128, 2011.

[27] C. Scheffler and J. M. Odobez, "Joint adaptive colour modelling and skin, hair and clothing segmentation using coherent probabilistic index maps," in Proc. British Machine Vision Association-British Machine Vision Conference, 2011

[28] T. H. Dat and C. Guan, "Feature selection based on fisher ratio and mutual information analyses for robust brain computer interface," in Porc. IEEE International Conference on Acoustics, Speech and Signal Processing, pp. I-337, 2007.

[29] M. Kaya, Feature selection and Classification on Gene Expression Data, Master Thesis, Gazi Universty, Graduate School of Natural Sciences, Ankara, 2014

[30] R. O. Duda, P. E. Hart, and D. G. Stork, Pattern Classification Second Edition, 2000.

[31] A. Altınörs, E. Avc1, and Z. Biçer, "Using of the bayes decision rules classifier for digital modulation recognition system," E- Journal of New World Sciences Academy, vol. 3, no. 1, 2008.
[32] E. Alpaydin, "Introduction to machine learning (adaptive computation and machine learning series," The MIT Press Cambridge, 2004.

[33] Y. Terzi, N. Murat, and M. A. Cengiz, "Bayesian hypothesis test and bayes factor," e- Journal of New World Sciences Academy, vol. 3, no. 2, pp-321-329, 2008.

[34] A. Karabulut, "Bayesian scene classification," Master Thesis, Hacettepe Universty, Graduate School of Natural Sciences, Ankara, 2006.

[35] J. C. Dunn, "A fuzzy relative of the ISODATA process and its use in detecting compact well-separated clusters," Well-Separated Clusters, J. Cybern., pp. 32-57, 1973.

[36] J. C. Bezdek, C. Coray, R. Gunderson, and J. Watson, (1981). Detection and characterization of cluster substructure i. linear structure: Fuzzy c-lines. SIAM Journal on Applied Mathematics, vol. 40, no. 2 pp. 339-357, 1981.

[37] M. Issı and A. Y. Camurcu, "Applied performance determination of k-means, k-medoids and fuzzy c-means algorithms," Journal of Istanbul Ticaret Üniversitesi Graduate School of Natural Sciences, vol. 6, no. 11, pp. 31-45, 2007.

[38] S. Naz, H. Majeed, and H. Irshad, "Image segmentation using fuzzy clustering: A survey," in Porc. 2010 6th International Conference on Emerging Technologies, 2010.

[39] E. Doğanay, S. Kara, and H. K. Özçelik, "Automatic segmentation of the lungs from HRCT scans by using fuzzy c- means clustering," in Porc. the Fifth International Symposium on Sustainable Development, 2014.

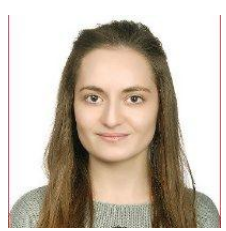

Nazan Kemaloğlu is a computer engineer and a postgraduate student at the Süleyman Demirel University

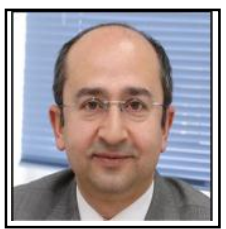

Tuncay Aydoğan received the $\mathrm{PhD}$ degree in 2005 from Sakarya University. He is currently an associated professor of Suleyman Demirel University. His research interests include smart systems, fuzzy logic, automatic control and industrial networks.

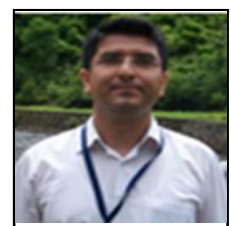

Sedat Metlek got the $\mathrm{PhD}$ degree in 2015 from Süleyman Demirel University. He is currently an assistant professor of Mehmet Akif Ersoy University. $\mathrm{He}$ is interested in image processing, artificial neural systems. 